\title{
The Comparative Mental Health Responses Between Post- Musculoskeletal Injury and Post-Concussive Injury Among Collegiate Athletes: A Systematic Review
}

\author{
Joseph Sabol, PT, DPT ${ }^{1}$, Cecelia Kane, PT, DPT ${ }^{1}$, Mark P Wilhelm, PT, DPT, PhD², Jennifer C Reneker, PT, PhD³, Megan \\ Burrowbridge Donaldson, PT, PhD, FAAOMPT ${ }^{2}$ a \\ ${ }^{1}$ Department of Physical Therapy, Walsh University, ${ }^{2}$ School of Medicine, Physical Therapy Program, Tufts University, ${ }^{3}$ School of Population Health, \\ Department of Population Health Sciences, University of Mississippi Medical Center (UMMC) \\ Keywords: musculoskeletal injury, movement system, depression, concussion, athletic injuries, anxiety \\ https://doi.org/10.26603/001c.18682
}

\section{International Journal of Sports Physical Therapy}

Vol. 16, Issue 1, 2021

\section{Background}

The average annual national estimate of injuries sustained by collegiate athletes is 210,674 , which encompasses both those of a musculoskeletal and a concussive nature. Although athletic injuries are sustained through physical means and produce physical symptoms, sports-related injuries may be a stressor among athletes that is related to mental health.

\section{Purpose}

The purpose of this systematic review is to summarize existing literature describing mental health responses in collegiate athletes with a concussion compared to those with a musculoskeletal injury.

\section{Study Design}

Systematic Review

\section{Methods}

Systematic searches of PubMed, CINAHL, Scopus, ProQuest, and SportDiscus were completed. The Preferred Reporting Items for Systematic Reviews and Meta-Analyses (PRISMA) guidelines were utilized. Methodological quality was assessed using the Joanna Briggs Institute (JBI) Critical Appraisal Tool. Data extracted from the included articles included the study design, number of participants, type of injury, sex, age, sport participation, outcome measures, and time to return to play.

\section{Results}

A total of six articles were included. Peak depressive symptoms in athletes who sustain a concussion or musculoskeletal injury occur within one-week post-injury. No significant differences between the concussive and musculoskeletal groups anxiety scores were found at baseline or at each follow-up session. Athletes from both groups were found to be returning to their respective sports with anxiety scores representative of clinical anxiety.

\section{Conclusion}

Similar trends in depressive and anxiety symptoms at various time points post-injury were observed in athletes with both musculoskeletal and concussive injuries. This study identified that athletes were returning to play before their psychological symptoms had

\footnotetext{
a Corresponding author:

Megan Burrowbridge Donaldson PT, PhD, FAAOMPT

Tufts University School of Medicine;

Physical Therapy Program

Boston MA, 02111

Megan.Donaldson@tufts.edu
} 
returned to their baseline.

\section{Level of Evidence}

\section{INTRODUCTION}

The National Collegiate Athletic Association (NCAA) is composed of 1,117 Colleges and Universities, encompassing 19,750 sports teams, and including nearly half a million college athletes. ${ }^{1}$ Of these athletes, the average annual national estimate of injuries is 210,674 encompassing those of a musculoskeletal and a concussive nature. ${ }^{2}$ A concussion is an injury that results from the rapid translational or rotational movement of the brain within the skull. This rapid movement can result in damage to or disruption of the functional units of the brain which affects brain metabolism and results in primary physical symptoms including but not limited to headaches, dizziness, sensitivity to light and sound, or loss of balance and coordination. ${ }^{3}$ In contrast, a musculoskeletal injury is typically tissue-level or structural damage to the bone, tendon, muscle, ligaments, or a combination of these structures due to supraphysiologic stress that exceeds the intrinsic stability of the musculoskeletal apparatus. ${ }^{4}$ These type of injuries result in primary symptoms of pain, weakness, swelling, stiffness, sensory deficits, and disability. ${ }^{5}$

Although athletic injuries are sustained through physical means and produce physical symptoms, sports-related injuries have been shown to be a depression-linked stressor among collegiate athletes. ${ }^{6-8}$ Psychological responses are a primary symptom in concussed athletes due to damage of the neural structures that contribute to emotional responses in the brain, while they are a secondary symptom in musculoskeletal injuries related to the experience of damage. 3,6 More specifically, primary cognitive symptoms of a concussion may include memory or concentration deficits along with emotional changes including depression, anxiety, and irritability. ${ }^{3}$ These emotional changes are seen in musculoskeletal injuries as well. However, it is the athlete's perception of the injury, not the injury itself, which results in psychological responses. ${ }^{9,10}$

A survey by The Association for University and College Counseling Center Directors (AUCCCD) found anxiety (48.2\%), followed by depression (34.5\%), to be the most frequent mental health experiences among college students. ${ }^{11}$ Collegiate athletes represent a subset of this population with additional stressors placed upon them from their respective sports. In terms of depression, symptoms include loss of interest or pleasure in activities once enjoyed, difficulty thinking, concentrating or making decisions, and loss of energy or increased fatigue. ${ }^{12}$ For athletes, this could include difficulty making decisions on the field, loss of selfidentity, and indifference towards a sport once found enjoyable.

Athletes suffering from post-injury anxiety may experience fear of a return to play, fear of re-injury, and fear of disappointing coaches and peers. Anxiety presents as a feeling of agitation and restlessness in response to certain situations characterized by symptoms of unease, nervousness, or worry about an event. ${ }^{13}$ Anxiety can be further subdivided into two components: state and trait anxiety. Trait anxiety is an uninterrupted personality trait, that is, an individual tendency to perceive negative experiences as threatening, which in turn increases the individual's level of anxiety. ${ }^{13}$ Whereas, state anxiety is defined as a transitory emotional state that consists of feelings of apprehension and tension experienced in a particularly stressful situation and characterized by consciously perceived subjective feelings of tension and apprehension. ${ }^{13}$ For athletes, state anxiety may be a potential result of an athletic injury. Furthermore, research has found that concussed athletes with pre-injury baseline trait anxiety did not have increased post-concussion depression and state anxiety symptoms, indicating that they are two separate components. ${ }^{7}$

Given the prevalence of depression and anxiety in collegiate students and the potential for athletic injuries to negatively impact mental health, albeit, via potentially different mechanisms, it is important to explore whether there are differences in mental health responses after injury for collegiate athletes, based on the type of injury sustained. Research is limited on the long-term effects of both types of injuries and the subsequent quality of life. Therefore, the purpose of this systematic review is to summarize existing literature describing mental health responses in collegiate athletes with a concussion compared to those with a musculoskeletal injury.

\section{METHODS}

\section{STUDY DESIGN}

This systematic review was registered with PROSPERO, the international database of prospectively registered systematic reviews in health (CRD42018115296). The Preferred Reporting Items for Systematic Reviews and Meta-Analyses (PRISMA) guidelines were utilized during the search and reporting phase of this systematic review. PRISMA is a 27-item checklist utilized to improve the reporting of systematic reviews and meta-analyses. ${ }^{14}$

\section{SEARCH STRATEGY}

Articles were identified through a systematic computerized search of PubMed, CINAHL, Scopus, ProQuest, and SPORTDiscus. Search strategies included MeSH terms, keywords, and text words related to collegiate athletes, concussions, musculoskeletal injuries, and mental health responses. The search strategy was originally optimized for PubMed and adapted for other databases using database specific terminology. No restrictions were placed on the search in terms of date of publication or type of research design. The initial search of published articles was performed on November 1, 2018 and was re-run on August 30, 2019 to include the most recent studies. The full PubMed search strategy can be found in Appendix 1. 


\section{ELIGIBILITY CRITERIA}

To be eligible for inclusion, articles were required to meet the following inclusion criteria: 1) compare mental health responses of collegiate athletes who experienced either a concussive or musculoskeletal injury during their competitive season; 2) include a diagnosis of musculoskeletal injury by a physician, athletic trainer, or therapist; and 3) defined concussive injuries as a diagnosis by a physician and/or onfield signs and symptoms such as observed or reported acceleration or deceleration of the head, any observable alteration in mental status and/ or any self-reporting symptoms such as headache, loss of consciousness, nausea, balance problems, or difficulty reading or concentrating. Articles that were written in a non-English language or contained only concussive or only musculoskeletal injuries were excluded.

\section{STUDY SELECTION}

Titles and abstracts were reviewed independently by two authors. In situations of disagreement regarding inclusion eligibility, the two authors came to an agreement through discussion. Full-text articles were then reviewed independently by two authors. Disagreements were again discussed between the two authors in order to formulate a final decision. Cohen's unweighted kappa was calculated to assess inter-rater reliability during the title- abstract and full- text screen. Using this metric, the strength of agreement for a Kappa of 0.0-0.20 was defined as slight, 0.21-0.40 was fair, 0.41-0.60 was moderate, $0.61-0.80$ was substantial, and $0.81-1.00$ was defined as almost perfect. ${ }^{15}$

\section{METHODOLOGICAL QUALITY OF INCLUDED STUDIES}

The Joanna Briggs Institute (JBI) Critical Appraisal Tools for use in JBI Systematic Reviews: Checklist for Cohort Studies was used to assess the methodological quality of the included studies. This appraisal tool is utilized to determine the extent to which a study has addressed the possibility of bias in its design, conduct, and analysis. The results of this appraisal can then be used to inform synthesis and interpretation of the results of the study. ${ }^{16}$ The tool consists of 11 questions applicable to cohort designs and is a guide for researchers to determine if a study should be selected based on the stated inclusion criteria. If the critical appraisal tool leads researchers to uncover a large source of bias in a study, it should be excluded. Two authors independently assessed all included articles for methodological quality. Disagreements between the two authors were settled through discussion. Cohen's unweighted kappa was calculated for the quality assessment process to determine the strength of agreement between the two authors.

\section{RESULTS}

\section{STUDY SELECTION}

The systematic electronic search yielded 1621 results. After removing duplicates, 1442 titles and abstracts were screened with a reliability of $k=0.89$ (95\%CI, 0.83 to 1.0 ). Nine articles were included for full-text review, yielding a reliability of $k=1.0$ (95\%CI, 1.0 to 1.0$)$.

After full-text review, six studies met the inclusion criteria for this review. Studies were excluded during the fulltext review process for the following reasons: 1) it was a systematic review, literature review, or thesis, 2) the manuscript was not written in the English language, 3) the article was in an inaccessible journal, 4) did not isolate data on collegiate athletes, 4) data were not collected on both concussive and musculoskeletal injuries, and 5) mental health outcomes post-injury were not included. The study screening process is shown in Figure 1.

\section{DATA EXTRACTION}

One author extracted data from the included studies using a standardized form. A separate author independently verified all the extracted data to ensure data accuracy. Extracted data included study characteristics such as 1) study design, 2) sample size, 3) sample demographic characteristics, 4) return to play time, 5) outcome measures, and 5) statistical data including the means and standard deviations (SD) for outcome variables of interest. These outcomes of interest included those related to depression and anxiety and were measured by various outcome measures (State-Trait Anxiety Inventory, Centers for Epidemiological Studies Depression Scale, and Profile of Mood States). Statistical values of fear of re-injury and return to play were analyzed.

\section{OUTCOME/SUMMARY MEASURES}

The State-Trait Anxiety Inventory is a self-reporting 40-item questionnaire that includes separate measures of state anxiety (20 items) and trait anxiety (20 items). The state anxiety measure assesses how the subject feels in the present moment, whereas the trait anxiety measure assesses how the subject generally feels. Each item is given a weighted score of 1 (low level of anxiety) to 4 (high level of anxiety); with a maximum possible score of 80 for both the state anxiety measure and the trait anxiety measure. ${ }^{17}$

The Profile of Mood States (POMS) is a 65-item adjective checklist designed to measure the transient emotional states of tension-anxiety, depression-dejection, fatigue-inertia, vigor-activity, confusion-bewilderment, and angerhostility. ${ }^{18}$ A modified version of the POMS was developed for sport settings. Two items used to assess depression were deleted and five items designed to assess esteem-related effect were added. The final instrument contained 40 adjectives which referred to seven different mood states: fatigue, anger, vigor, tension, esteem-related affect, confusion, and depression. Responses are made on a 0-4 scale with 0 labeled as "not at all" and 4 labeled "extremely." It was concluded that this modified form has acceptable psychometric properties. ${ }^{19}$

The Centers for Epidemiological Studies Depression Scale (CES-D) is a 20-item self-reporting scale designed to measure the depressive symptomology in the general population. Each item is rated on a 4-point, with 0 indicating "rarely or none of the time" and 3 indicating "most or all of the time.” The CES-D has been validated with the collegiate population. ${ }^{20}$ 
Table 1. Quality assessment of included studies, using the Joanna Briggs Institute (JBI) Critical Appraisal Tool

\begin{tabular}{|c|c|c|c|c|c|c|c|c|c|c|c|c|}
\hline $\begin{array}{l}\text { First } \\
\text { Author, } \\
\text { Year }\end{array}$ & Q.1 & Q.2 & Q.3 & Q.4 & Q.5 & Q.6 & Q.7 & Q.8 & Q.9 & Q.10 & Q.11 & Total \\
\hline $\begin{array}{l}\text { Covassin, } \\
2014\end{array}$ & Yes & Yes & Yes & Yes & No & Yes & Yes & No & Yes & No & Yes & $8 / 11$ \\
\hline Guo, 2018 & Yes & Yes & Yes & Yes & Yes & Yes & Yes & Yes & Yes & No & Yes & $\begin{array}{l}10 / \\
11\end{array}$ \\
\hline $\begin{array}{l}\text { Hutchison, } \\
2009\end{array}$ & Yes & Yes & Yes & Yes & Yes & Yes & Yes & No & Yes & No & Yes & $9 / 11$ \\
\hline $\begin{array}{l}\text { Mainwaring, } \\
2010\end{array}$ & Yes & Yes & Yes & Yes & Yes & Yes & Yes & No & Yes & No & Yes & $9 / 11$ \\
\hline $\begin{array}{l}\text { Roiger, } \\
2015\end{array}$ & Yes & Yes & Yes & Yes & No & Yes & Yes & No & Yes & No & Yes & $8 / 11$ \\
\hline
\end{tabular}

Q.1 Were the two groups similar and recruited from the same population?

Q.2 Were the exposures measured similarly to assign people to both exposed and unexposed groups?

Q.3 Was the exposure measured in a valid and reliable way?

Q.4 Were confounding factors identified?

0.5 Were strategies to deal with confounding factors stated?

Q.6 Were the groups/participants free of the outcome at the start of the study (or at the moment of exposure)?

Q.7 Were the outcomes measured in a valid and reliable way?

Q.8 Was the follow up time reported and sufficient to be long enough for outcomes to occur?

Q.9 Was follow up complete, and if not, were the reasons to loss to follow up described and explored?

Q.10 Were strategies to address incomplete follow up utilized?

Q.11 Was appropriate analysis used?

\section{RISK OF BIAS IN INCLUDED STUDIES}

The JBI Critical Appraisal tools for Cohort Studies is assessed out of 11-points. It was determined that one study ranked a quality score of 10 , two studies ranked 9, and three studies ranked at an 8. Common themes with the articles include not addressing strategies to deal with confounding factors and an insufficient follow-up time. Agreement between authors for quality assessment of included studies was a kappa score of 0.95 (95\%CI, 0.86 to 1.0). Although no studies were excluded based on their quality assessment score, the reader must take caution in over interpreting the results from studies of lower quality. The quality assessment scores of individual studies are shown in Table 1.

\section{STUDY CHARACTERISTICS}

The total number of injured participants in all included studies is 824, with 632 experiencing a musculoskeletal injury and 192 experiencing a concussive injury. Mean age for athletes with musculoskeletal injury ranged from 19.23 (SD $\pm 2.34)$ to $22.84(\mathrm{SD} \pm 1.77)$ years. While athletes with concussion ranged from 19.4 (SD \pm 1.45 ) to 22.54 (SD \pm 1.73 ) years of age. Three studies did not report mean age. Further, 559 participants were male, and 265 were female.

Within the six included articles, ${ }^{21-26}$ five included football and basketball, ${ }^{21-25}$ four included volleyball, ${ }^{21-24}$ three included wrestling, ${ }^{21,22,25}$ soccer, $21,22,24$ and field hockey, ${ }^{21,22,24}$ two included softball,21,22 baseball, ${ }^{21,22}$ hockey, ${ }^{23,24}$ lacrosse, ${ }^{23,24}$ and rugby, ${ }^{23,24}$ and one included mountain biking ${ }^{24}$ and cheerleading. ${ }^{26}$ One study did not report the type of sport injury breakdown. ${ }^{26}$ The mean time from the concussive injury until subject's ability to return to play ranged from eight days to one month. The mean time from the musculoskeletal injury until subject's ability to return to play ranged from eight days to one year. Five of the studies first measurement of depression and anxiety symptoms were at baseline, meaning prior to an injury occurring. ${ }^{21-25}$ One of the studies first measurement of depression and anxiety symptoms was within 72-hours postinjury. $^{26}$ A summary of the study characteristics is presented in Table 2.

\section{QUALITATIVE REVIEW OF STUDIES}

\section{DEPRESSION MEASURES}

\section{EFFECT OF TIME ON DEPRESSION MEASURES OF CONCUSSED ATHLETES}

Five of the included articles reported on depressive symptoms for post-concussive injuries. ${ }^{22-26}$ Depressive symptoms were assessed pre-season prior to any type of injury (baseline) and at varying time periods after an injury was sustained. Four articles agreed that peak depressive symptoms in athletes who sustain a concussion occur within one-week post-injury, which is a significant difference when compared to baseline scores. More specifically, peak depressive symptoms ranged from within 72-hours postinjury, ${ }^{26}$ within 96 -hours post-injury, ${ }^{23}$ four days post-injury, ${ }^{24}$ and seven days post-concussive injury. ${ }^{25}$ However, Hutchinson et al. reported that peak scores that occurred within 96-hours post-injury are not statistically significantly different from baseline. ${ }^{23}$ Guo et al., reported peak 


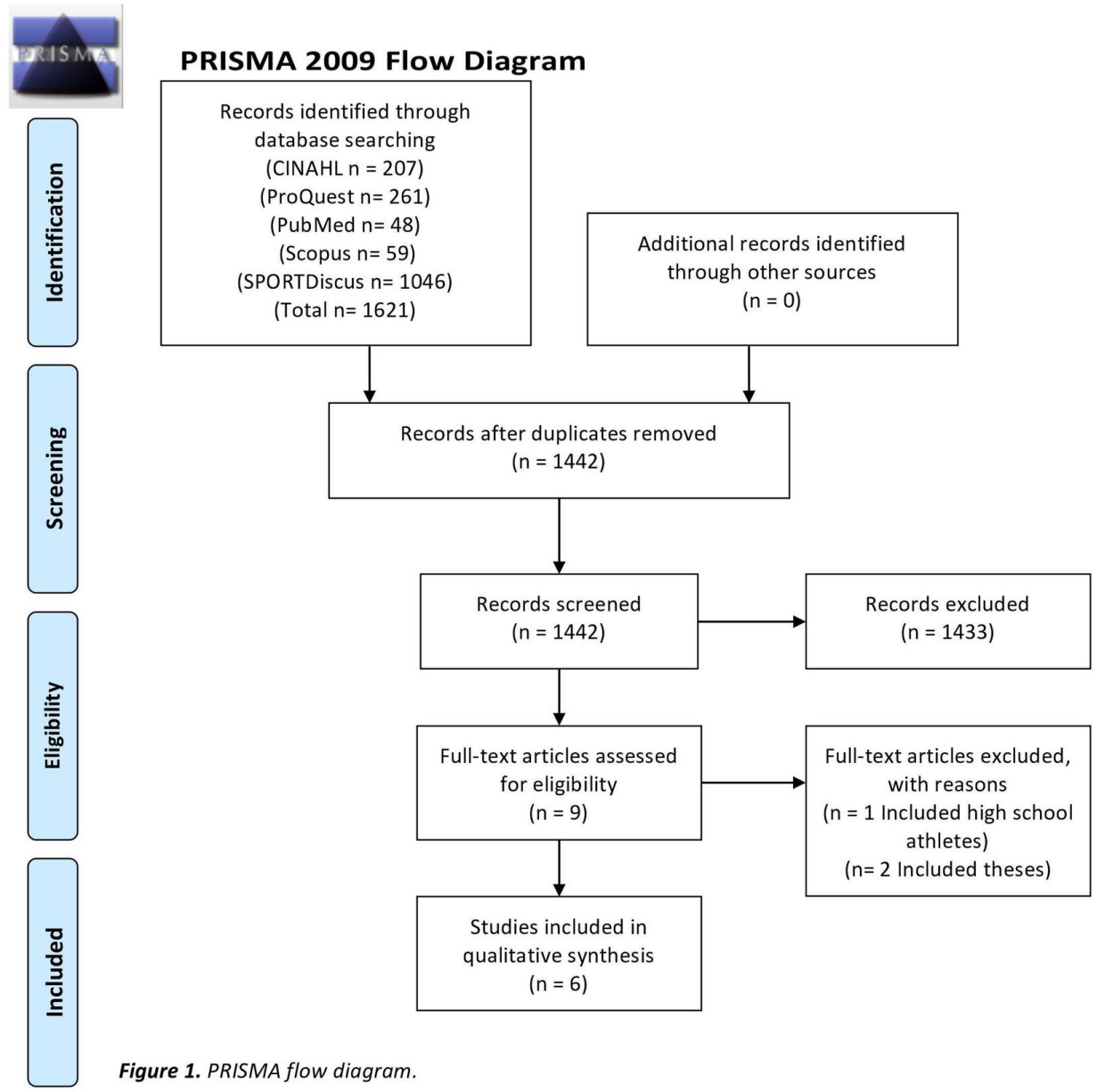

Figure 1. PRISMA flow diagram

depressive symptoms at one month post-concussive injury. ${ }^{22}$ Furthermore, four articles are in agreement that depressive symptoms post-concussive injury steadily decrease after the peak depressive scores. ${ }^{23-26}$ Hutchinson et al. and Mainwaring et al. showed a decrease in depressive scores up to two weeks, while Roiger et al., shows a decrease up until three months. ${ }^{23-25}$ Turner et al. shows a continual decrease in depressive symptoms from within 72-hours post-injury through return to play. ${ }^{26}$

\section{EFFECT OF TIME ON DEPRESSION MEASURES OF MUSCULOSKELETAL INJURED ATHLETES}

Five of the included articles reported on depressive symptoms for musculoskeletal injuries. ${ }^{22-26}$ Four articles found that depressive symptoms peak within one week of sustaining a musculoskeletal injury $22,23,25,26$ while Mainwaring et al. reported peak depressive scores at 11 days postinjury. ${ }^{24}$ However, Hutchinson et al. reported that these peak depressive scores are not statistically significantly different from pre-season baseline scores. ${ }^{23}$ All articles are in agreement that depressive symptoms gradually decrease over time, however at varying time points reported in each study. ${ }^{22,23,25,26}$ Reduction in depression symptoms varied from two weeks post-injury, ${ }^{23} 23$ days post-injury, ${ }^{24}$ three months post-injury, ${ }^{25}$ and until return to play (which dif- fered for each athlete). ${ }^{22-26}$

\section{EFFECT OF TIME ON DEPRESSION MEASURES BETWEEN CONCUSSED AND MUSCULOSKELETAL INJURED ATHLETES}

Interestingly, Roiger et al. found that both the post-concussive and post-musculoskeletal injury athletes had peak depressive scores at one week. However, the concussed participants' scores decreased from one week to one month, while the musculoskeletal injury group remained elevated over baseline at the one month time point before decreasing toward baseline at three months. ${ }^{25}$ Hutchinson et al. found neither group to differ from baseline scores, or differ from one another. ${ }^{23}$ Guo et al. found that while both musculoskeletal injured and concussive groups scored similar at pre-season baseline and one week post-injury on depressive symptoms, the concussive group scored higher on depressive symptoms at one month after injury than the musculoskeletal group. ${ }^{22}$ Mainwaring et al. found that concussed athletes displayed almost three times more depressive symptoms four-days post-injury compared to pre-season baseline measures. Meanwhile, the athletes with musculoskeletal injuries reported over seven times more depression 11 days post-injury than at baseline. ${ }^{24}$ 


\section{ANXIETY MEASURES}

Three of the included articles reported on anxiety symptoms for both post-concussive and post-musculoskeletal injuries. ${ }^{21,22,26}$ Two articles reported trait anxiety symptoms measured at pre-season baseline and state anxiety symptoms for all post-injury follow-ups. ${ }^{21,22}$ One article only reported state anxiety symptoms for all post-injury followups. $^{26}$

\section{EFFECT OF TIME ON ANXIETY MEASURES OF CONCUSSED INJURED ATHLETES}

For concussive injuries, all three articles found that the highest reported anxiety score was the earliest measured score, whether that be baseline or within 72-hours postinjury. ${ }^{21,22,26}$ All three articles also found a decrease in anxiety symptoms from baseline or 72-hours post-injury to one-week post-injury. ${ }^{21,22,26}$ Two articles found an increase in anxiety scores from one-week post-injury to re- turn to play. 22,26 Turner et al. found that within 72-hours post-injury, $73.3 \%$ of the post-concussive group scored anxiety mean scores that exceeded the state anxiety threshold for clinical anxiety (scores $>38) .26$

\section{EFFECT OF TIME ON ANXIETY MEASURES OF MUSCULOSKELETAL INJURED ATHLETES}

For musculoskeletal injuries, all three articles found a decrease in anxiety symptoms from baseline or within 72-hours post-injury to one-week post-injury. ${ }^{21,22,26}$ Guo et al. found decrease in anxiety symptoms from one-week to return to play. ${ }^{22}$ Turner et al. found an increase in anxiety symptoms from one-week to return to play. ${ }^{26}$ Additionally, these authors found that within 72-hours postinjury, $66.7 \%$ of post-musculoskeletal group had anxiety mean scores that exceeded the state anxiety threshold for clinical anxiety. ${ }^{26}$ 
Table 2. Characteristics of Included Studies.

\begin{tabular}{|c|c|c|c|c|c|c|c|}
\hline $\begin{array}{l}\text { First } \\
\text { Author, } \\
\text { Year }\end{array}$ & Study Design & $\begin{array}{l}\text { Participants } \\
\text { (n) }\end{array}$ & Gender & $\begin{array}{l}\text { Mean Age } \\
\text { (SD) }\end{array}$ & Sports Involved & Average Return to Play Time (SD) & Outcome Measure(s) \\
\hline $\begin{array}{l}\text { Covassin, } \\
2014^{21}\end{array}$ & Cohort Study & $\begin{array}{l}\operatorname{MSK}(63) \\
\operatorname{CONC}(63)\end{array}$ & $\begin{array}{l}M=92 \\
F=34\end{array}$ & $\begin{array}{l}\mathrm{MSK}= \\
22.84 \\
(1.77) \\
\text { CONC= } \\
22.54 \\
(1.73)\end{array}$ & $\begin{array}{l}\text { Football, wrestling, softball, } \\
\text { soccer, volleyball, basketball, } \\
\text { field hockey, baseball }\end{array}$ & $\begin{array}{l}\text { MSK: } 8.90 \text { (13.31) days CONC: } 8.87 \\
\text { (13.67) days }\end{array}$ & $\begin{array}{l}\text { State-Trait Anxiety Inventory } \\
\text { (STAI) Profile of Mood States }\end{array}$ \\
\hline $\mathrm{Guo}_{22} 2018$ & $\begin{array}{l}\text { Prospective } \\
\text { Cohort Study } \\
\text { with Repeated } \\
\text { Measures }\end{array}$ & $\begin{array}{l}\text { MSK (526) } \\
\text { CONC (71) }\end{array}$ & $\begin{array}{l}M= \\
400 F= \\
197\end{array}$ & & $\begin{array}{l}\text { Football, wrestling, baseball, } \\
\text { basketball, soccer, softball, } \\
\text { field hockey, volleyball }\end{array}$ & $\begin{array}{l}\text { MSK: } 1 \text { week }=311,1 \text { month }=107,3 \\
\text { months }=74,6 \text { months }=27,12 \\
\text { months }=7 \text { CONC: } 1 \text { week }=63,1 \\
\text { month= } 8\end{array}$ & $\begin{array}{l}\text { Centers for Epidemiological } \\
\text { Studies Depression Scale (CES- } \\
\text { D) State-Trait Anxiety } \\
\text { Inventory (STAI) }\end{array}$ \\
\hline $\begin{array}{l}\text { Hutchinson, } \\
2009^{23}\end{array}$ & $\begin{array}{l}\text { Prospective } \\
\text { Longitudinal } \\
\text { Cohort Study }\end{array}$ & $\begin{array}{l}\operatorname{MSK}(14) \\
\operatorname{CONC}(20)\end{array}$ & $\begin{array}{l}M=24 \\
F=10\end{array}$ & $\begin{array}{l}\text { MSK= } \\
19.23 \\
(2.34) \\
\text { CONC= } \\
20.05 \\
(1.82)\end{array}$ & $\begin{array}{l}\text { Basketball, football, hockey, } \\
\text { lacrosse, rugby, volleyball }\end{array}$ & $\begin{array}{l}\text { MSK: } 8.36 \text { (3.54) days CONC: } 12.68 \\
\text { (19.03) days }\end{array}$ & Profile of Mood States (POMS) \\
\hline $\begin{array}{l}\text { Mainwaring, } \\
2010^{24}\end{array}$ & $\begin{array}{l}\text { Prospective } \\
\text { Mixed Cohort } \\
\text { Design with } \\
\text { Repeated } \\
\text { Measures }\end{array}$ & $\begin{array}{l}\operatorname{MSK}(7) \\
\operatorname{CONC}(16)\end{array}$ & $\begin{array}{l}M=13 \\
F=10\end{array}$ & & $\begin{array}{l}\text { Basketball, field hockey, } \\
\text { football, hockey, lacrosse, } \\
\text { mountain biking, rugby, } \\
\text { soccer, volleyball }\end{array}$ & CONC: 25 days & Profile of Mood States (POMS) \\
\hline $\begin{array}{l}\text { Roiger, } \\
2015^{25}\end{array}$ & $\begin{array}{l}\text { Descriptive } \\
\text { Epidemiologic } \\
\text { Study }\end{array}$ & $\begin{array}{l}\operatorname{MSK}(7) \\
\operatorname{CONC}(7)\end{array}$ & $\begin{array}{l}M=13 \\
F=1\end{array}$ & & $\begin{array}{l}\text { Wrestling, football, } \\
\text { basketball }\end{array}$ & $\begin{array}{l}\text { MSK: } 12.7 \text { (7.6) days CONC: } 16.9 \\
\text { (19.03) days }\end{array}$ & $\begin{array}{l}\text { Centers for Epidemiological } \\
\text { Studies Depression Scale (CES- } \\
\text { D) }\end{array}$ \\
\hline $\begin{array}{l}\text { Turner, } \\
2017^{26}\end{array}$ & $\begin{array}{l}\text { Prospective } \\
\text { Cohort Study }\end{array}$ & $\begin{array}{l}\text { MSK (15) } \\
\text { CONC (15) }\end{array}$ & $\begin{array}{l}M=17 \\
F=13\end{array}$ & $\begin{array}{l}\text { MSK= } \\
19.95 \\
(1.15) \\
\text { CONC= } \\
19.4 \\
(1.45)\end{array}$ & $\begin{array}{l}\text { Division I intercollegiate } \\
\text { athletics program or } \\
\text { cheerleading team }\end{array}$ & $\begin{array}{l}\text { MSK: } 10.85 \text { (9.63) days CONC: } \\
13.93 \text { (4.88) days }\end{array}$ & $\begin{array}{l}\text { State-Trait Anxiety Inventory } \\
\text { (STAI) Profile of Mood States } \\
\text { (POMS) }\end{array}$ \\
\hline
\end{tabular}

$\mathrm{SD}=$ standard deviation; $\mathrm{M}=$ male, $\mathrm{F}=$ female, $\mathrm{MSK}=$ musculoskeletal, $\mathrm{CONC}=$ concussion 


\section{EFFECT OF TIME ON ANXIETY MEASURES BETWEEN CONCUSSED AND MUSCULOSKELETAL INJURED ATHLETES}

All three articles found no significant differences between the concussive and musculoskeletal groups anxiety scores at baseline or at each follow-up session. ${ }^{21,22,26}$ Turner et al. found anxiety scores that exceeded the state anxiety threshold for clinical anxiety within 72-hours post-injury and at return to play. ${ }^{26}$ Turner et al. also found that even though both groups means dropped to lower levels of state anxiety at one week post-injury, over half of the participants in each group (53.3\%) still exceeded the state anxiety threshold for clinical anxiety. ${ }^{26}$

\section{DISCUSSION}

This systematic review explored the comparative mental health responses between post-musculoskeletal injury and post-concussive injury among collegiate athletes. The results of the current review illustrate similar depressive patterns in athletes who have sustained a sports-related concussion or musculoskeletal injury from pre-injury measurements to return to play. A distinctive pattern was also shown for anxiety in both injury groups from pre-injury measurements to return to play.

For anxiety, studies reported scores decreasing between the first recorded measurement and one-week post-injury and then increasing from one-week post-injury to return to play for both injury groups. One exception was presented in Guo and colleagues who found athletes reported a continual decrease in anxiety symptoms in the musculoskeletal group from the pre-injury baseline measurement to return to play. This outlier could be due to athletes receiving rehabilitation services and progressing to pre-injury abilities, thereby reducing their anxiety about their injury.

Two interesting findings were observed for depressive symptoms amongst the two groups. First, there was a peak in depressive symptoms at the first measurement post-injury followed by a steady decline in symptoms at subsequent time points for both injury groups. ${ }^{22-25}$ The elevation in psychological symptoms post-injury could represent a reduction in the hormones that are naturally produced by the body, endogenous opiates, which are generated during exercise. $^{27}$ These hormones are associated with feelings of comfort, safety, and happiness, which can be interrupted when there is a disruption in the athletes training program, leading to a psychological disturbance. ${ }^{27,28}$

Alternatively, the second discovery found that with concussive injuries, the lowest point of depressive symptoms occurred at one-week post-injury, then increased at subsequent time points. ${ }^{22-26}$ This can be attributed to a higher risk for post-injury depression the longer an athlete faces post-concussive symptoms. ${ }^{22}$ Additionally, because a concussion is an internal injury rather than external, athletes may have difficulty understanding or reasoning as to their inability to return to play if they cannot see the injury. Resultantly, the mismatch between the patient's anticipated or expected outcome and their actual ability may alter the course of depression. ${ }^{22}$ Concussed athletes likely expect to recover in a short period of time and these athletes may not be prepared to cope with any prolongation of that recovery. A prolonged recovery results in increased concern about further sports participation and extent of the injury. ${ }^{29}$

It has been hypothesized that it may not be the injury itself that triggers a psychological response, but rather the removal from athletic activity participation. ${ }^{30,31}$ The degree to which an individual identifies with the athlete role is termed athletic identity, which can contribute to an athlete's sense of self. When there is a disruption in this perception, an athlete may question their self-worth due to a strong connection between their athletic identity and their self-identity. ${ }^{32}$ Kroshus and colleagues found that athletes with greater athletic identity have an increased likelihood that post-injury symptoms will go under-reported. ${ }^{33}$ Athletes may fear that time away from the sport will equate to a loss of individuality, and therefore are willing to compete rather than sacrifice their perception of themselves. It is not only their perception of themselves that is at risk but also how others perceive them. Athletes face external pressures from teammates, coaches, and peers, motivating them to hide their injury symptoms because it is more beneficial for the team if the athlete misses the shortest amount of time possible after sustaining an injury. ${ }^{33}$

Several studies have outlined the benefit of educating athletes on post-injury management in regard to mental health. Athletes will often not report psychological disturbances because they do not realize that such symptoms may be related to injury, which often leads to under-reporting and denial of symptoms. ${ }^{34}$ It has been shown that education may lead to decreasing the stigma of "sitting out" while concussed; however, some argue the long term efficacy of such education is unremarkable. ${ }^{35,36}$ Murray et al. argues that it is unlikely that preventative measures will have much impact without a radical change in the perception of injuries within the sports culture. ${ }^{37}$ Athletes tend to downplay mental or psychological distress due to the expectations of strength, stability, and unwavering "mental toughness" that is ingrained in the sports culture. ${ }^{38}$ Injuries, and thus secondary effects of injuries, may only be minimized if the aggressive attitude of sports culture is more conscientious of an athlete's overall well-being.

An additional area of further research may be to determine the long-term effects of injury on quality of life. The included articles did not present data on time points post-return to play. An article by Richmond et al. reports an $18 \%$ prevalence of a major depressive disorder, depression not otherwise specified, or persistent depressive disorder one year after even a minor injury. ${ }^{39}$ It would be of interest to observe if depressive or anxiety symptoms linger after return to play and in what aspects of the athlete's life are affected and to what extent. Similarly, a study by Montenigro et al. reported cumulative head impacts exposure predicts later-life depression, apathy, executive dysfunction, and cognitive impairment in former high school and college football players. ${ }^{40}$ More information such as this would be beneficial in minimizing the taboo of optimal self-care after injury, which sports culture does not encourage, and aid in providing long-term physiological and psychological care.

Administering both pre-injury and post-injury patientcentered outcome measures can provide clinicians with im- 
portant information regarding the extent of an athletic injury. Outcome measures that assess both physical and psychological symptoms should be utilized to ensure the athlete is being treated holistically and allow monitoring of patient progression or regression in an objective manner over time. ${ }^{41,42}$ In addition to outcome measures used within the included studies the Profile of Mood States (POMS), Centers for Epidemiological Studies Depression Scale (CES-D), and State-Trait Anxiety Inventory (STAI); the Anterior Cruciate Ligament-Return of Sport after Injury (ACL-RSI) Scale and Sport Concussion Assessment Tool-5th Edition (SCAT5) can be helpful in screening for an athletes psychological symptoms specific to their injuries. These tools have been developed to assist coaches and athletes in making the appropriate decision in regards of return to play. The development of these tools helped legitimize the idea that there is a significant emotional response to athletic injury as well as during the subsequent rehabilitation process. The findings of this systematic review indicate that although anxiety symptoms decreased at subsequent time points from baseline, over half of the included athletes had scores that would be considered clinically anxious. Therefore, it is imperative for athletes to become cognizant of their psychological symptoms post-injury, to acknowledge the need to seek professional assistance when necessary. ${ }^{22}$

\section{LIMITATIONS}

Limitations exist in the current study that could affect the strength of the results presented. First, only six articles met the inclusion criteria for this systematic review and of these six, four articles included a small sample size of 50 or fewer participants. In addition, the articles included were deficient in quantitative data. For example, four of the six included articles displayed their findings in a line graph rather than presenting specific mean score values in either the manuscript or tables. Furthermore, the articles included were lacking descriptive data within their population, such as disclosing which sports were included along with the number of participants involved in each sport. Lastly, each study provided their own unique definition of "musculoskeletal injury" and did not further subcategorize the group based on severity of injury. This may have attributed to the wide range of return to play times and subsequent reporting of depression and anxiety. Providing the above information could lead to new discoveries and insight on areas in need of further research.

\section{CONCLUSION}

Similar patterns in depressive and anxiety symptoms at various time points post-injury were observed in both musculoskeletal and concussive injuries. Although anxiety scores may fluctuate over the course of recovery, a majority of collegiate athletes had scores representative of clinical anxiety throughout subsequent encounters from baseline to return to play. This indicates that athletes were returning to play before their psychological symptoms were back to their baseline. The long-term effects of mental health outcomes secondary to athletic injury as well as information on return to play criteria were not addressed. Further research should focus on an appropriate length of time between injury and return to play, as well as longitudinal data on psychological effects post-athletic injury.

\section{CONFLICTS OF INTEREST}

No potential conflict of interests were reported by the authors.

This work was conducted while authors CC, JS, MD, and MW were at Walsh University. JR was at the University of Mississippi Medical Center during the completion of this work.

Submitted: December 11, 2019 CDT, Accepted: June 16, 2020 CDT 


\section{REFERENCES}

1. National Collegiate Athletic Association. What is the NCAA? November 2018. https://www.ncaa.org/ab out/-resources/media-center/ncaa-101/what-ncaa. Accessed March 8, 2019.

2. Kerr ZY, Marshall SW, Dompier TP, Corlette J, Klossner DA, Gilchrist J. College Sports-Related Injuries - United States, 2009-2010 Through 2013-2014 Academic Years. MMWR Morb Mortal Wkly Rep. 2015;64(48):1330-1336. doi:10.15585/mmwr.mm 6448a2

3. Echlin P. Definition of Concussion. Sports Concussion Library. 2019. http://sportconcussionlibrar y.com/definition-concussion/. Accessed March 8, 2019.

4. Zelle BA, Fu FH. Pathogenesis of soft tissue and bone repair. In: Rehabilitation for the Postsurgical Orthopedic Patient. 3rd ed. St. Louis, MO: Elsevier; 2013:2-14. https://doi.org/10.1016/b978-0-323-0774 7-7.00001-0.

5. Lee S. Approach to the patient with a musculoskeletal problem. In: Lee S, ed. Musculoskeletal Injuries and Conditions: Assessment and Management. New York, NY: Springer Publishing Company; 2017:1-6,9.

6. Green S, Weinberg R. Relationships among athletic identity, coping skills, social support, and the psychological impact of injury in recreational participants. J Appl Sport Psychol. 2001;13(1):40-59.

7. Yang J, Peek-Asa C, Corlette JD, Cheng G, Foster DT, Albright J. Prevalence of and risk factors associated with symptoms of depression in competitive collegiate student athletes. Clin J Sport Med. 2007;17(6):481-487. doi:10.1097/jsm.0b013e318 $15 \mathrm{aed} 6 \mathrm{~b}$

8. Appaneal R, Levine B, Perna F, et al. Measuring postinjury depression among male and female competitive athletes. J Sport Exerc Psychol. 2009;31(1):60-76.

9. Wiese-Bjornstal D, Smith A, Shaffer S, et al. An integrated model of response to sport injury: Psychological and sociological dynamics. J Appl Sport Psychol. 1998;10(1):46-69.

10. Kiliç Ö, Aoki H, Goedhart E, et al. Severe musculoskeletal time-loss injuries and symptoms of common mental disorders in professional soccer: A longitudinal analysis of 12-month follow-up data. Knee Surg Sport Tr A. 2017;26(3):946-954. doi:10.100 7/s00167-017-4644-1
11. LeViness P, Bershad C, Gorman K. The association for university and college counseling center directors annual survey. 2017:1-72. https://www.aucccd.org/ass ets/documents/Governance/2017\%20aucccd\%20surve y-public-apr26.pdf.

12. Parekh R. What is depression? American Psychiatric Association. January 2017. https://www.ps ychiatry.org/patients-families/depression/what-is-de pression. Accessed March 8, 2019.

13. Ferreira C, Silva R. The spielberger inventory like a tool for assess the trait and state anxiety. In: Bradley A, ed. Trait and State Anxiety: Assessment, Predictors and Outcomes. NY: Nova Science Publishers; 2016:2-4.

14. Moher D, Liberati A, Tetzlaff J, Altman DG, The PRISMA Group. Preferred reporting items for systematic reviews and meta-analyses: The PRISMA statement. PLoS Med. 2009;6(7):e1000097. doi:10.137 1/journal.pmed.1000097

15. Landis J, Koch G. The measurement of observer agreement for categorical data. Biometrics. 1977;33(1):159-174.

16. Munn Z, Moola S, Riitano D, Lisy K. The development of a critical appraisal tool for use in systematic reviews addressing questions of prevalence. Int J Health Policy Manag. 2014;3(3):123-128. doi:10.15171/ijhpm.2014.71

17. Spielberger C, Gorsuch R, Lushene R, eds. StateTrait Anxiety Inventory for Adults (Form x). Palo Alto, CA: Consulting Psychologists Press; 1970.

18. McNair D, Droppleman L, Lorr M. Profile of Mood States, POMS. San Diego, CA: Educational and Industrial Testing Service; 1971.

19. Grove R, Prapavessis H. Preliminary evidence for the reliability and validity of an abbreviated profile of moods states. Int J Sport Psychol. 1992;23:93-109.

20. Radloff LS. The CES-D scale: A self-report depression scale for research in the general population. Appl Psychol Meas. 1977;1(3):385-401. do $\mathrm{i}: 10.1177 / 014662167700100306$

21. Covassin T, Crutcher B, Bleecker A, Heiden EO, Dailey A, Yang J. Postinjury anxiety and social support among collegiate athletes: A comparison between orthopaedic injuries and concussions. J Athl Train. 2014;49(4):462-468. doi:10.4085/1062-6059-4 9.2.03 
22. Guo J, Yang J, Yi H, Singichetti B, Stavrinos D, Peek-Asa C. Differences in postinjury psychological symptoms between collegiate athletes with concussion and orthopedic injuries. Clin J Sport Med. 2018;0:1-6. doi:10.1097/jsm.0000000000000621

23. Hutchison M, Mainwaring LM, Comper P, Richards DW, Bisschop SM. Differential emotional responses of varsity athletes to concussion and musculoskeletal injuries. Clin J Sport Med. 2009;19(1):13-19. doi:10.10 97/jsm.0b013e318190ba06

24. Mainwaring LM, Hutchison M, Bisschop SM, Comper P, Richards DW. Emotional response to sport concussion compared to ACL injury. Brain Injury. 2010;24(4):589-597. doi:10.3109/02699051003610508

25. Roiger T, Weidauer L, Kern B. A longitudinal pilot study of depressive symptoms in concussed and injured/nonconcussed national collegiate athletic association division I student-athletes. J Athl Train. 2015;50(3):256-261. doi:10.4085/1062-6050-49.3.83

26. Turner S, Langdon J, Shaver G, et al. Comparison of psychological response between concussion and musculoskeletal injury in collegiate athletes. Sport Exerc Perform Psychol. 2017;6(3):277-288.

27. Schwarz L, Kindermann W. Beta-endorphin, adrenocorticotropic hormone, cortisol and catecholamines during aerobic and anaerobic exercise. Eur J Appl Physiol.

28. Hoffman P. Physical activity and mental health. In: Morgan WP, ed. Physical Activity and Mental Health. Series in health psychology and behavioural medicine. Philadelphia, PA: Taylor and Francis; 1997:163-177.

29. Asken B, Mccrea M, Clugston J, et al. "Playing through it": Delayed reporting and removal from athletic activity after concussion predicts prolonged recovery. J Athl Train. 2016;51(4):329-335.

30. Chan CS, Grossman HY. Psychological effects of running loss on consistent runners. Percept Mot Skills. 1988;66(3):875-883. doi:10.2466/pms.1988.66.3.875

31. Lyketsos CG, Lopez O, Jones B, Fitzpatrick AL, Breitner J, DeKosky S. Prevalence of neuropsychiatric symptoms in dementia and mild cognitive impairment: Results from the cardiovascular health study. JAMA. 2002;288(12):1475-1483. doi:10.1001/ja ma.288.12.1475

32. Brewer B, Van Raalte J, Linder D. Athletic identity: Hercules' muscles or Achilles' heel? Int J Sport Psychol. 1993;24:237-254.
33. Kroshus E, Kubzansky LD, Goldman RE, Austin SB. Norms, athletic identity, and concussion symptom under-reporting among male collegiate ice hockey players: A prospective cohort study. Ann Behav Med. 2015;49(4):95-103. doi:10.1007/s12160-0 14-9636-5

34. Nixon HLI. A social network analysis of influences on athletes to play with pain and injuries. J Sport Social Issues. 1992;16(2):127-135. doi:10.1177/019372 $\underline{359201600208}$

35. Tjong VK, Baker HP, Cogan CJ, Montoya M, Lindley TR, Terry MA. Concussions in NCAA Varsity Football Athletes: A qualitative investigation of player perception and return to sport. JAAOS: Global Research and Reviews. 2017;1(8):e070. doi:10.5435/jaa osglobal-d-17-00070

36. Kurowski BG, Pomerantz WJ, Schaiper C, Ho M, Gittelman MA. Impact of preseason concussion education on knowledge, attitudes, and behaviors of high school athletes. J Trauma Acute Care Surg. 2015;79:S21-S28. doi:10.1097/ta.0000000000000675

37. Murray I, Murray A, Robson J. Sports Concussion: Time for a culture change. Clin J Sport Med. 2015;25(2):75-77.

38. Carr C, Davidson J. Positioning the experts. In: Brown G, ed. Mind, Body, and Sport: Understanding and Supporting Student-Athlete Mental Wellness. Indianapolis, IN: National Collegiate Athletic Association; 2014:17.

39. Richmond TS, Amsterdam JD, Guo W, et al. The effect of post-injury depression on return to preinjury function: A prospective cohort study. Psychol Med. 2009;39(10):1709-1720. doi:10.1017/s003329170 9005376

40. Montenigro PH, Alosco ML, Martin BM, et al. Cumulative Head Impact Exposure Predicts Later-Life Depression, Apathy, Executive Dysfunction, and Cognitive Impairment in Former High School and College Football Players. J Neurotrauma. 2017;34(2):328-340. doi:10.1089/neu.2016.4413

41. Snyder AR, Parsons JT, Valovich McLeod TC, Curtis Bay R, Michener LA, Sauers EL. Using disablement models and clinical outcomes assessment to enable evidence-based athletic training practice, part I: Disablement models. J Athl Train. 2008;43(4):428-436. doi:10.4085/1062-6050-43.4.428

42. Valovich McLeod TC, Snyder AR, Parsons JT, Curtis Bay R, Michener LA, Sauers EL. Using disablement models and clinical outcomes assessment to enable evidence-based athletic training practice, part II: disablement models. J Athl Train. 2008;43(4):437-445. doi:10.4085/1062-6050-43.4.437 


\section{SUPPLEMENTARY MATERIALS}

\section{Appendix 1}

Download: https://ijspt.scholasticahq.com/article/18682-the-comparative-mental-health-responses-between-postmusculoskeletal-injury-and-post-concussive-injury-among-collegiate-athletes-a-systematic-review/attachment/ 49200.docx 